\title{
Urteil eröffnet keine Schlacht um Rabattgutscheine
}

\begin{abstract}
Mit seinem Urteil vom 21.05.2015 (Az. I ZR 183/13) hat der Bundesgerichtshof (BGH) den langjährigen Streit um die Zahnarztgutscheine auf dem Internetportal www.groupon.de entschieden. Der BGH erklärte die Angebote zahnärztlicher Leistungen auf der Seite zwar grundsätzlich für zulässig, wer jedoch meint, mit dem formal zugunsten von Groupon gefällten Urteil sei nun der Patientengewinnung über entgeltliche Gutscheine ein Freibrief erteilt, hat das Kleingedruckte des Urteils offenbar überlesen: Die von der Zahnärztekammer Nordrhein gesehene Gefahr, gegen die Berufsordnung zu verstoßen, bleibt.
\end{abstract}

\section{Der Fall}

Der Betreiber der Internetplattform schloss mit seinen Partnern, darunter Zahnärzten, sogenannte Kooperationsverträge. Auf dem Portal wurden den registrierten Nutzern zahnärztliche Leistungen in Gutscheinform zu rabattierten Pauschalpreisen angeboten. Die so gekauften Leistungen wurden ausschließlich von den Zahnärzten erbracht, die Groupon „von allen Ansprüchen der Gutscheinerwerber freistellen“"mussten, hieß es in den Allgemeinen Geschäftsbedingungen (AGB) von Groupon. Für die Vermittlung zahlte der Zahnarzt als Provision etwa die Hälfte des eingenommenen Pauschalpreises.

Die Zahnärztekammer Nordrhein sah in diesem Modell unter anderem die berufsrechtswidrige Gewährung eines Entgelts für die Zuweisung von Patienten und nahm Groupon unter anderem auf Unterlassung der Kooperationsverträge mit Zahnärzten in Anspruch.

\section{Die Entscheidung}

Streitig war aus prozessualen Gründen vor dem BGH nur noch die Untersagung der Verträge selbst. Die Werbung für zahnärztliche Pauschalpreise hatte das Kammergericht Berlin rechtskräftig wegen Verstoßes gegen die GOZ für unzulässig erklärt. Der BGH befand die Kooperationsverträge zwar für zulässig und hob das insoweit anderslautende Urteil des Kammergerichts Berlin in diesem Punkt auf. Aber: Der Blick in die Begründung zeigt, dass die Zahnärztekammer mit ihrer Auffassung grundsätzlich richtig liegt.

\section{Zuweisung gegen Entgelt bleibt verboten}

Zwar sei es dem Zahnarzt verboten, so der BGH, für die Zuführung von Patienten ein Entgelt zu gewähren. Er dürfe aber eine Plattform dafür vergüten, dass sie seine zahnärztlichen Leistungen vermittle. Für die Abgrenzung hier sei maßgeblich, ob sich ein vertraglich mit Groupon verbundener Zahnarzt bei der Behandlung eines Gutscheinerwerbers nicht am Patientenwohl, sondern an eigenen wirtschaftlichen Interessen orientiere. (Nur)

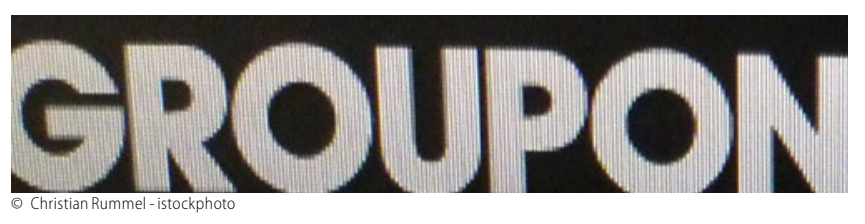

das zu verhindern, sei Sinn und Zweck des Verbotes der „Zuweisung gegen Entgelt“. Entscheidend sei im Ergebnis die Bedeutung der oben zitierten Klausel.

Der BGH bewertete diese Klausel als mehrdeutig. Es sei unklar, ob der Zahnarzt den Betreiber von allen Ansprüchen des Patienten freistellen müsse, auch von Rückzahlungsansprüchen für den Fall, dass der Zahnarzt die Behandlung zum Wohle des Gutscheinerwerbers ablehne. Damit greife der alte AGB-Grundsatz: Im Zweifel gegen den Verwender der AGB (hier: Groupon). Der BGH legte die Klausel dahin aus, dass nur Mängel- und Haftungsansprüche von der Klausel erfasst seien. Daher habe es für den Zahnarzt keine finanziellen Konsequenzen, wenn er zum Wohle des Patienten von einer Behandlung aus medizinischen Gründen absehe. Damit habe der Vertrag „dieselben Auswirkungen“ wie das „zulässige kostenpflichtige Zurverfügungstellen einer Internetplattform zum Anbieten freiberuflicher Leistungen“. Die Vereinbarung sei (noch gerade so) zulässig.

Fazit

Der BGH hat also offen gelassen, ob hier eine verbotene Zuweisung gegen Entgelt vorlag. Die Konstruktion gefährdet seines Erachtens im Ergebnis nicht die zahnärztliche Unabhängigkeit, und das auch nur, weil die AGB von Groupon mehrdeutig waren. Letztlich hat damit nur die Unklarheit der AGB von Groupon in den Verträgen mit den Zahnärzten zum Obsiegen in dem wettbewerbsrechtlichen Streit mit der Kammer geführt. Die Entscheidung öffnet also mitnichten die Schleuse für Rabattgutscheinschlachten um zahnärztliche oder sonstige heilkundliche Leistungen. Im Gegenteil: Zahnärzte laufen mit der Beteiligung an solchen Modellen unverändert Gefahr, gegen ihre Berufsordnung zu verstoßen.

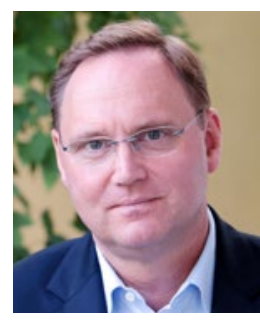

RA Michael Lennartz

www.heilberuferecht.eu 